\title{
Telemedicine Adoption by Different Groups of Physicians
}

\author{
Dragos Vieru ${ }^{1,2}$ and Anne-Marie Croteau ${ }^{1}$ \\ ${ }^{1}$ John Molson School of Business, Concordia University \\ ${ }^{2}$ McGill University Health Centre, Information Services
}

\author{
Contact person: \\ Anne-Marie Croteau, Ph.D. \\ Assistant Professor, Decision Sciences and MIS \\ John Molson School of Business \\ Concordia University \\ 1455, de Maisonneuve West, GM 209-13 \\ Montreal, Quebec, Canada, H3G 1M8 \\ Tel.: (514) 848-2983, Fax: (514) 848-2824 \\ Email: croteau@alcor.concordia.ca
}

HICSS-35 Information Technology in Health Care Track

Integrating Information Systems Theory and Health Informatics Research 


\title{
Telemedicine Adoption by Different Groups of Physicians
}

\author{
HICSS-35 Information Technology in Health Care Track
}

Integrating Information Systems Theory and Health Informatics Research

\begin{abstract}
This study addresses the factors that could affect the intention of physicians to adopt telemedicine technology. Based on the theoretical foundations of technology adoption models, a revised model is proposed and tested via a questionnaire with two groups of physicians that were, at the time of the survey, just about to use telemedicine technology. Group A is composed of physicians from a large urban healthcare provider institution involved in clinical, teaching, and research activities. An Intranet solution for teleradiology and teleconferencing based on ATM technology is being implemented. Physicians received no training regarding this technology. Group B is composed of physicians from rural areas who received training just before using the telemedicine network that links 43 sites in the same area. Results analyzed with PLS indicate that in both cases, physicians' perception of usefulness of telemedicine is positively related to their intention to adopt this technology. This is the only common result between the two groups. Physicians from group A have the intention to adopt telemedicine because its ease of use makes it sound useful. Physicians from group B perceive the ease of use of telemedecine as being associated with its usefulness, which is then related to their intention to adopt telemedicine. Specialists and researchers from group A indicated that their perceived effort and persistence is related to their perceived ease of use, which is linked with perceived usefulness. Both perceived ease of use and usefulness have an impact on their intention to adopt telemedecine, whereas the image they project by using it has no bearing on their intention to adopt telemedicine. Finally their perceived voluntariness of use has a negative and significant impact on their behavioral intention to adopt telemedicine. This result may be explained by the fact that these physicians, due to their heavy load of research and clinical practice, have less time to assess new technologies related to their work and they probably prefer that someone else do the legwork for them.
\end{abstract}




\section{Introduction}

The healthcare industry is now starting to grasp the impact that information technology can have on reshaping its activities. To help eradicate common problems such as, difficult access, rising costs and poor quality of healthcare, telemedicine is on the road to becoming an integral part of medical practice worldwide.

There are several definitions of telemedicine. "Telemedicine is the practice of medicine without the usual physician-patient physical confrontation, but instead via an interactive audio-video communication system" (Bird, 1975, as in Bashshur, Sanders, Shannon, 1997, p. 19). Industry Canada defines telemedicine as "the use of communications and information technology to deliver health and healthcare services and information over large and small distances" (Picot, 1998, p.9). With the advent of Internet/Intranet technologies, telemedicine can be perceived as a set of communication modalities that allow for the transmission of medical data, video images and audio between physicians and other healthcare providers. These technologies apply to clinical areas such as radiology, dermatology, pathology, surgery, cardiology, home healthcare and to teaching through teleconferencing. Some of the benefits of telemedicine include the ability of bringing healthcare services to the patient, reducing the time it takes to make diagnosis and treatment decisions and improving the continuity of care.

Telemedicine could be the solution to its medical woes, namely access and costs. Telehealth technology has a major role to play in the plans endorsed by health ministers across countries to amalgamate and redistribute medical services in cities and local communities. However, telemedicine can be a double-edged sword, as it can provide a means for institutional survival or the path to professional failure, depending on how it is presented to the buying population and how it is implemented.

This research is designed to provide academics and practitioners alike with a pragmatic explanation of key factors affecting the adoption of telemedicine. The general research question this paper examines is: What are the key factors that influence physicians' adoption of telemedicine? One of the reasons that telemedicine system implementations have failed in the past was the lack of physicians' adoption of the new technology, the poor quality of the technology and premature funding termination (Bashshur et al., 1997). With the 
emergence of province-wide telehealth networks it is crucial to address the physician technology adoption issue.

This paper puts forward a model of user adoption of information technology that is applicable to physicians. The proposed model combines a modified version of the Technology Acceptance Model (TAM) (Davis, 1989) with aspects of the Diffusion of Innovations Theory (DIT) (Rogers, 1995), in this way taking into account additional factors that might affect physicians' attitudes towards telemedicine. The study validates this model and addresses a pragmatic managerial need: avoiding the pitfalls of implementing telemedicine, stemming from millions of dollars invested into developing telemedicine programs by federal and provincial governments in recent years. The success of telemedicine requires an adopting organization to address both technological and managerial challenges.

\section{Theoretical background}

For the past decade, researchers have tried to create conceptual models that encompass the main factors that influence users to accept new technologies. Many times, academics have debated the issue of whether information technology (IT) is actually adopted by its intended users. This review emphasizes research that has tried to shed light on the determinants of user adoption, as this concept has been tackled theoretically and empirically in the academic literature on IT implementation. Studies that pertain to telemedicine technology adoption will also be addressed. User acceptance is a critical factor for IT adoption. User acceptance can be defined as: "the obvious willingness within a group to use IT for the tasks it is designed to support" (Dillon and Morris, 1996, p. 4). Reluctance of users to accept IT is a crucial hindrance to the success of the implementation of any new information system; user acceptance has been viewed as the pivotal factor in determining the success or failure of any IS project (Davis, Bagozzi and Warshaw, 1989).

The Technology Acceptance Model (TAM) developed by Davis (1989) proposes a method of evaluating user acceptance by assessing users' beliefs, attitudes, intentions and "actual computer adoption behavior". Davis postulated that behavioral intention to use IT was predominantly correlated with use. The main goal of TAM is to 
predict IT acceptance and shed light on design problems of new IS before users adopt the system (Dillon and Morris, 1996). TAM uses a set of two variables (perceived ease of use and perceived usefulness) employed in many computer technology acceptance contexts. This model was found to be much simpler and easier to use by most researchers and to be a more powerful model for establishing the variables influencing user acceptance of computer technology. TAM has proven to be successful in predicting and explaining use across a variety of new technologies

Roger's Diffusion of Innovations Theory provides a solid foundation for developing conceptual models that assess the impact of new IT on users, over time. The innovation decision process leading to institutionalization of use may be conceptualized as a sequence of steps where an individual goes from initial perception of an innovation, to the development of an attitude toward it, to a decision to adopt or reject it, to using it and finally reinforcing the adoption decision (Rogers 1995). Rogers defines adoption as “...the decision to make full use of an innovation as the best course of action available" (Rogers 1995, p.21).

In the last ten years, many researchers have tried to prove that TAM, enhanced with certain other constructs, is the model best suited to explore and explain user acceptance of new IT (Adams, Nelson and Todd, 1992; Igbaria, 1993; Compeau and Higgins, 1995; Szajna, 1996; Chang, 1998; Compeau, Higgins and Huff, 1999). Currently more and more academics realize that an all-encompassing model is hard to build. At the same time they recognize that every model they create has as a foundation, TAM. The emergence of this model represents the turning point in academics' and practitioners' endeavors to understand and predict user acceptance of new IT.

Only a few studies have been done to assess the impact of telemedicine on the actual or potential users of this particular technology. Succi and Walter (1999) proposed an extended Technology Acceptance Model to investigate physicians' acceptance of telemedicine. They argued that, unlike middle managers or MBA students who had been used as the target population in most IT acceptance studies, physicians enjoy authority and prestige in their environment. Information systems, in general, improve many users' - including physicians' - job performance. However certain technologies, like telemedicine, could to a certain extent, 
codify expert knowledge owned only by professionals. Certain physicians may see this process as a threat to their expertise. From here stems the problem of physician reluctance to adopt telemedicine. The authors proposed a model that takes into account additional factors that could affect physicians' attitude toward telemedicine. They introduced a new factor, perceived usefulness towards professional status. Unfortunately the authors did not empirically test the model. Hu et al. (1999) used data obtained from physicians in selected hospitals in Hong Kong, to assess the explanatory force of TAM in the case of physician acceptance of telemedicine technology. The study's outcomes showed reasonable support for the utilization of this research model. The authors suggested that there is a need for adding other constructs to the model or integrating it with other IT acceptance models, in order to enhance its explanatory power in the healthcare milieu. These kinds of modified or integrated research models can provide a more thorough explanation of the understanding of IT acceptance by physicians.

\section{Research model and hypotheses}

This study melds the existing user technology adoption literature, telemedicine research and practitioner goals. In this way a contribution to IT adoption research is expected by extending the validity and applicability of existing research models to healthcare providers. Also a better understanding of telemedicine technology adoption is anticipated because of the significant growth of IT investment in healthcare organizations across the globe, and especially in Canada. The proposed model, pictured in Figure 1, attempts to answer the general research question: What are the key factors that influence physicians' decision to adopt telemedicine technology? The theoretical model for the study combines constructs taken from the Technology Acceptance Model (Davis, 1989) and constructs from the Diffusion of Innovations Theory (Rogers, 1995) in a complementary manner. The underlying foundation for our model is a simplified TAM. When end user perceptions are captured prior to adoption, the dependent variable should be the intention to adopt rather than the intention to use. According to TAM, studies need to be specific with regards to the target behavior of 
interest (Davis, 1989). This study's goal is to examine adoption; hence the dependent variable is the intention to adopt.

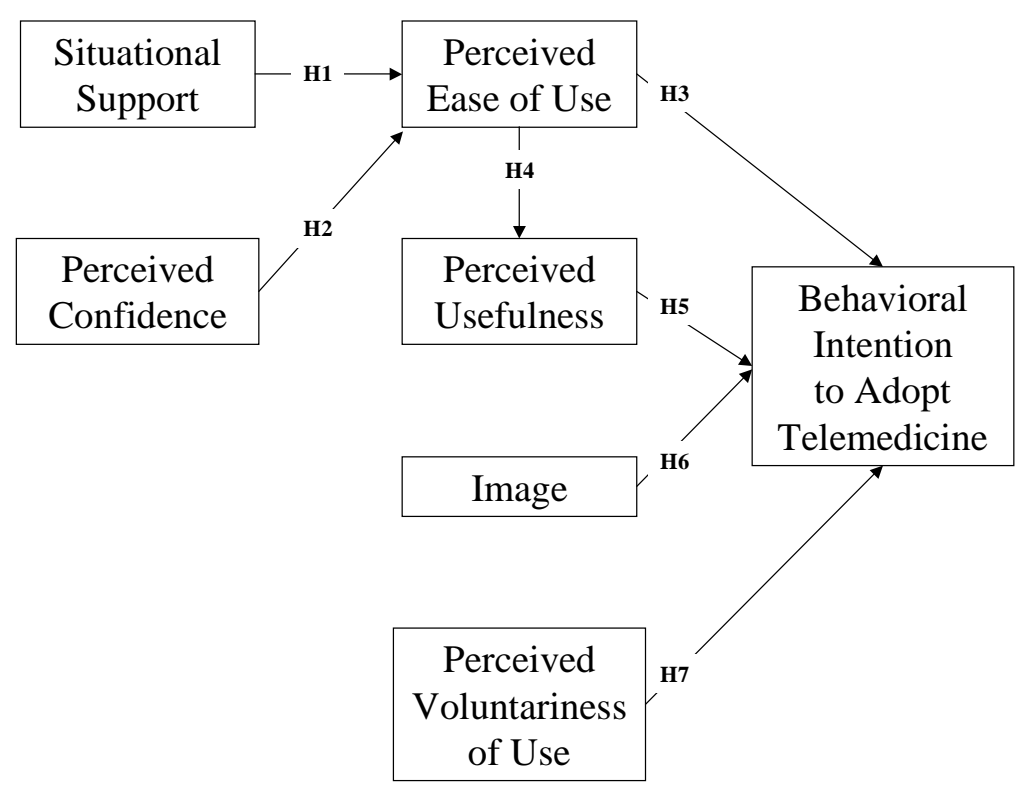

Fig.1 Research Model

There are a few differences between our model and Davis' original model. The first difference is that the attitude construct was removed in order to simplify the model (Davis et al., 1989; Chau, 1996; Igbaria et al., 1997). While empirically testing his original model, Davis et al. (1989) found, in the outcomes of their studies, that the attitude-behavior relationship was non-significant. They therefore removed the attitude construct from their original model. The second difference is that a link was added between perceived ease of use (PEOU) and behavior intention to adopt (BI). This was done because other empirical studies found a significant relationship between these two constructs (Moore and Benbasat, 1991; Chau, 1996). According to other researchers' suggestions (Chau, 1996; Jackson et al., 1997; Agarwal and Prasad, 1999) behavioral intention to adopt was used as a dependent variable instead of actual use. This was done because TAM hypothesizes that behavior intention is the major determinant of use behavior (Davis, 1989). This is the third difference. Another difference is the inclusion of the situational support (SS) and perceived effort and 
persistence (PEP) constructs in our model as antecedents of perceived ease of use. These two constructs were derived from the computer self-efficacy construct (CSE), as suggested by Venkatresh and Davis (1996). According to Marakas, Yi and Johnson (1998), "self-efficacy is a composite of numerous factors, each of which serve to have a direct effect on the final individual judgment and on the relationship of that judgment to the actual performance" p.128. The relationships between both constructs and the perceived ease of use were respectively tested in our previous research and were found to be positive and significant.

Finally, two more constructs, namely image and perceived voluntariness of use (PVU) were included in our model. These constructs originated from literature on the Diffusion of Innovations Theory. This theory, as shown in the literature review, provides a set of attributes that could affect an individual's opinion on the innovation, prior to adoption. In their study, Moore and Benbasat (1991) found that image and PVU were among the other main characteristics that were identified as having a significant impact on the decision to adopt an IT innovation. The image construct encompasses the perception that adoption of the technology may enhance one's status in one's social system (Moore and Benbasat, 1991). This pertains to the physician's belief that his perceived professional status may be altered by the adoption of telemedicine technology. Perceived voluntariness of use was added to the model to assess whether or not the adoption of telemedicine is entirely voluntary. As shown in Moore and Benbasat's study this research examines the impact that perceived voluntariness of use has on intention to adopt.

In this research, telemedicine technology adoption is seen as a physician's psychological state with regards to his/her intention to adopt this particular technology. The target technology was telemedicine in general, rather than specific telehealth programs such as teleradiology, telesurgery, etc. The reason behind this decision was that telemedicine is still in the adoption stage, which makes it difficult to assess user technology adoption based on specific telemedicine technologies. Nevertheless, the outcomes of this study will provide academics and practitioners alike with insights relevant to technology adoption in general and telemedicine in particular. 
The following hypotheses will be tested in order to attain this paper's goal:

H1:Physicians' situational support is positively linked to their perception of the ease of use of telemedicine.

H2: Physicians' perceived effort and persistence is positively linked to their perception of the ease of use of telemedicine.

Both of these hypotheses were supported in our previous research. Hypothesis H1 refers to the relationship between situational support and perceived ease of use of telemedicine and hypothesis $\mathrm{H} 2$ addresses the link between perceived confidence and perceived ease of use of telemedicine.

H3:Physicians' perception of the ease of use of telemedicine is positively linked to their behavioral intention to adopt it.

H4: Physicians' perception of the ease of use of telemedicine is positively linked to their perception of its usefulness.

These two hypotheses are based on suggestions made by Davis et al. (1989) who argued that perceived ease of use has a direct impact on behavioral intention. Hypothesis $\mathrm{H} 3$ was formulated taking into account that the easier a system is to use, the greater the perception that the technology being adopted will support the user's professional needs is (Jackson et al., 1997). Hypothesis H4 has been validated in other studies (Chau, 1996; Jackson et al., 1997).

H5:Physicians' perception of the usefulness of telemedicine is positively linked to their behavioral intention to adopt it.

A direct relationship between perceived usefulness and behavioral intention to adopt is established based on previous results obtained by Davis et al. (1989) and Adams et al. (1992).

H6: Physicians' image is positively linked to their behavioral intention to adopt telemedicine.

H7: Physicians' perception of voluntariness of use of telemedicine is positively linked to their behavioral intention to adopt it. 
The last two hypotheses were formulated following recommendations from Moore and Benbasat (1991) who found that there is support for considering image as a separate factor that influences behavioral intention. They also argued that perceived voluntariness of use is an important attribute when consideration has to be given to whether the potential users are free to adopt or reject a new technology.

\section{Methodology}

\subsection{Variables}

This model combines well-validated constructs from the Technology Acceptance Model with elements from the Diffusion Innovation Theory (Davis et al., 1989; Moore and Benbasat, 1991; Venkatresh and Davis, 1996; Hu et al., 1999). Preliminary measurements of the model's variables were obtained from the above mentioned studies using a five point Likert scale with values ranging from 1 - strongly disagree to 5 - strongly agree. Most of the constructs' items were re-worded to fit telemedicine.

Situational support defines the users' perceptions regarding the appropriateness of the training approach and IS support, while the perceived effort and persistence construct refers to the amount of perceived effort necessary to complete a computer related task (Marakas et al. 1998). Situational support (3 items) and perceived effort and persistence ( 2 items) were two constructs derived from the computer self-efficacy construct (Venkatresh and Davis, 1996). Perceived ease of use is defined as "the degree to which a person believes that using a particular system would be free of effort" (Davis, 1989, p. 320). Perceived usefulness refers to "the degree to which a person believes that using a particular system would enhance his/her job performance" (Davis, 1989, p. 320). Perceived ease of use (5 items) and perceived usefulness ( 7 items) were adopted from Hu et al. (1999) who used them among 421 physicians from hospitals in Hong Kong. The image construct assesses the perception that adoption of the technology may enhance one's status in one's social system (Moore and Benbasat, 1991). Perceived voluntariness of use assesses whether or not the adoption of telemedicine is entirely voluntary. Image ( 2 items) and perceived voluntariness of use ( 2 items) were based on Moore and Benbasat's (1991) instrument and adopted from Karahanna et al. (1999). The behavior intention to 
adopt telemedicine refers to the actions planned by physicians on experimenting telemedecine. This construct, which was composed of 4 items, was based on Davis' original construct and modified to make it relevant to telemedicine.

\subsection{Data collection}

The data for this study were gathered by means of a survey questionnaire administered to physicians in preselected specialties who practice medicine in healthcare institutions. In group A, physicians working within an institution that is not only a healthcare provider, but is also a teaching hospital and a world-renowned medical research institution, were chosen as respondents. An Intranet solution for teleradiology and teleconferencing based on ATM technology is being implemented. All four sites of this institution will be able to hold teleconferences involving physicians and researchers alike. The choice of contacting 260 physicians, specialized in emergency medicine, surgery, orthopedics, oncology, respirology, urology and radiology, was based on the likelihood of their involvement with telemedicine programs in the near future since they will probably be among the first to use telemedicine technology.

Group B was composed of physicians from healthcare institutions in rural areas that were targeted because of the newly implemented telemedicine network that links 43 sites throughout the area. The questionnaire was sent to 140 physicians who had participated in at least one continuing medical education (CME) session via teleconferencing.

The questionnaire was pre-tested by 10 physicians from five different specialties (general surgery, emergency medicine, oncology, orthopedic surgery and radiology). They were randomly chosen from group A and were eliminated from the final list. After a few adjustments, the final instrument was administered via mail, to physicians in both groups. The survey was accompanied by a cover letter stating the nature and purpose of the study. Participation was voluntary and confidentiality and anonymity were assured. The physicians were asked to respond within two weeks of receipt of the package. 
Of the 390 questionnaires distributed, 87 from group A and 42 from group B were completed and returned. Two from group A were rejected because of too many unanswered questions, leaving 127 for the data analysis. This represents a 32.5 percent response rate. Respondents averaged respectively for each group 16 and 17.7 years in practice in their area of specialty. Among the respondents, the male-to-female ratio was approximately 7:1 for both groups. There was not a significant difference regarding the intention to adopt telemedicine among physicians from the two data sources, but differences among physicians from the same source (especially from group B) categorized according to their job tenure were observed. No significant differences were found between early and late respondents regarding their answers to the questionnaire, suggesting that the threat of non-response bias would not be a factor.

\section{Results}

The research model was analyzed using Partial Least Squares (PLS), a second-generation multivariate technique that allows for the testing of the psychometric properties of the scales used to measure a variable, as well as the strength and direction of the relationships among variables (Cassel, Hackl and Westlund, 1999). PLS was developed to accommodate small size groups (contrary to LISREL) as long they are ten times larger than the number of items contained in the most substantial construct (Chin, Marcolin and Newsted, 1996). The data do not have to be normally distributed when using this technique. PLS is comprised of two sets of equations: the assessment of the measurement model, and the assessment of the structural model. The former implies the calculation of the item reliability, convergent validity and the discriminant validity. The latter entails determining the appropriate nature of the relationships (paths) between the measures and constructs. The estimated path coefficients indicate the sign and the power of the relationships while the item's weights and loadings indicate the strength of the measures (Hulland, 1999). The computer program used for this analysis was PLS Graph developed by Chin and Fee (1995). 


\subsection{Assessment of the measurement model}

Item reliability shows whether the indicators measure this construct only. Only items with loading equal or greater than 0.50 were kept for inclusion in the scales (Hair, Anderson, Tatham and Black, 1992). The final number of items per construct is shown in table 1 . Convergent validity assesses the degree to which items that should be related to a construct are in reality related. To do so, the rho coefficient was used and its value is determined by the respective loading of items. The criterion established by Nunnally (1967) pertaining to the reliability of the construct is that any construct having a rho value equal or greater than 0.70 should be kept. This criterion is abided by. The rho values are also presented in Table 1 . Discriminant validity reflects the degree to which each construct is unique. In order to assess the discriminant validity of the measures, two aspects have to be verified. First, the items associated with a construct correlate more highly with each other than with items associated with other constructs in the model. Second, the Average Variance Extracted (AVE) calculated for each measure is higher than all the variances shared between the measures (Fornell and Larker, 1981). The assessment of the measurements was conducted and the discriminant validity was successfully verified this time (see Table 1)

Table 1 Discriminant validity and construct reliability

\begin{tabular}{|c|c|c|c|c|c|c|c|}
\hline & $\begin{array}{c}\text { SS } \\
\rho=0,88\end{array}$ & $\begin{array}{c}\text { PEP } \\
\rho=0,88\end{array}$ & $\begin{array}{l}\text { PEOU } \\
\rho=0,89\end{array}$ & $\begin{array}{c}\text { PU } \\
\rho=0,88\end{array}$ & $\begin{array}{l}\text { IMAGE } \\
\rho=0,87\end{array}$ & $\begin{array}{c}\text { PVU } \\
\rho=0,90\end{array}$ & $\begin{array}{c}\text { BI } \\
\rho=0,87\end{array}$ \\
\hline SS & 0.714 & & & & & & \\
\hline PEP & 0.072 & 0.801 & & & & & \\
\hline PEOU & 0.053 & 0.096 & 0.675 & & & & \\
\hline PU & 0.068 & 0.062 & 0.399 & 0.689 & & & \\
\hline IMAGE & 0.070 & 0.050 & 0.099 & 0.345 & 0.685 & & \\
\hline PVU & 0.001 & 0.005 & 0.029 & 0.063 & 0.057 & 0.829 & \\
\hline BI & 0.059 & 0.041 & 0.234 & 0.494 & 0.260 & 0.084 & 0.641 \\
\hline
\end{tabular}




\subsection{Assessment of the structural model}

Results of the assessment of the structural model are indicated in Figure 2 and Figure 3 for Group A and Group B respectively. Hypothesis H1 that referred to the relationship between situational support and perceived ease of use of telemedicine was not supported for both groups. Hypothesis H2 tested the link between perceived effort and persistence and perceived ease of use of telemedicine and was supported for group A ( path $\left._{\mathrm{a}}=0.306 ; \mathrm{p}<0.001\right)$. Hypothesis H3, which referred to the relationship between perceived ease of use and behavioral intention to adopt, was supported for group A ( path $\left._{\mathrm{a}}=0.142, \mathrm{p}<0.05\right)$. Hypothesis H4 referred to the relationship between perceived ease of use and perceived usefulness; was supported for both groups $\left(\right.$ path $_{\mathrm{a}}=0.618, \mathrm{p}<0.001 ;$ path $\left._{\mathrm{b}}=0.593, \mathrm{p}<0.001\right)$.

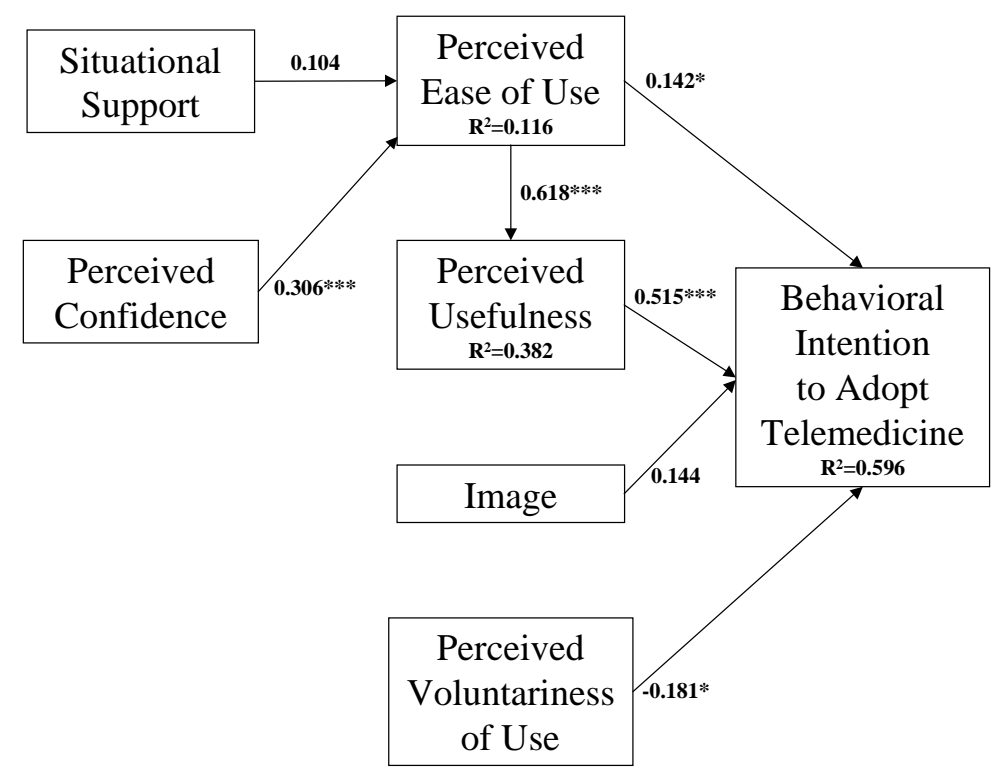

One-tail t-test: $*: \mathrm{p}<0.05 ; * *: \mathrm{p}<0.01 ; * * *: \mathrm{p}<0.001$

\section{Fig. 2 Results for group A $(n=85)$}

Hypothesis H5 tested the relationship between perceived usefulness and behavioral intention to adopt. A positive and significant relationship was observed for both groups $\left(\right.$ path $_{\mathrm{a}}=0.515, \mathrm{p}<0.001 ; \mathrm{path}_{\mathrm{b}}=0.591$, $\mathrm{p}<0.01)$. Hypothesis H6, which referred to the relationship between image and behavioral intention to adopt, 
was not supported in either group. Hypothesis H7, which tested for the existence of a positive impact of perceived voluntariness of use on behavioral intention to adopt, was not supported as well. Interestingly enough for group A, the perceived voluntariness of use has a negative and significant impact on their behavioral intention to adopt telemedicine $\left(\right.$ path $\left._{\mathrm{a}}=-0.181, \mathrm{p}<0.05\right)$.

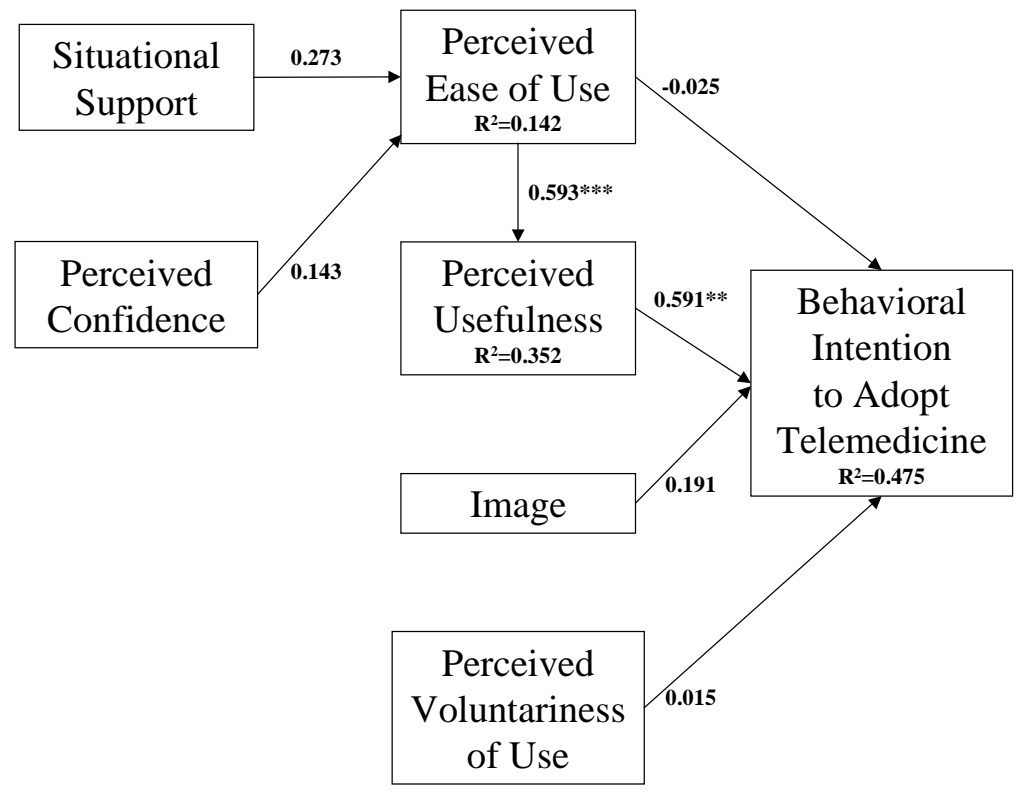

One-tail t-test: *: $\mathrm{p}<0.05 ; * *: \mathrm{p}<0.01 ; * * *: \mathrm{p}<0.001$

Fig. 3 Results for group $B(n=42)$

\section{Discussion}

In this study, TAM was modified to include additional constructs, namely image and perceived voluntariness of use, taken from the Innovations Diffusion Theory (Rogers, 1995), and situational support and perceived effort and persistence. A conceptual model was created that would better explain physician adoption of telemedicine technology. On one hand, perceived ease of use, usefulness and "non"-voluntariness of use counted for 59.6 variance in the intention to adopt for group A, and on the other hand, perceived usefulness only explained for 47.5 percent of the variance in intention to adopt for group B. 
Situational support was not significantly linked with perceived ease of use. This implies that physicians believe that they have the ability to perform their tasks well whatever the resources are, and regardless of the complexity of telemedicine technology. Perceived effort and persistence was also found to have a significant impact on perceived ease of use in the case of physicians from the teaching and academic areas (group A). This result can be explained by the fact that they have not received any training before, contrary to group B who did. Facing a novelty, physicians will relate their effort spent in prior experiences to their perception of telemedicine ease of use. They went through so many difficult tasks and learning experiences throughout their years of practice that they know that they have to be persistent and put some time and efforts to learn a new tool to make it eventually easy to use.

The significant association found for group A between perceived ease of use and behavioral intention to adopt telemedicine can be explained by the fact that these physicians are professionals and due to their general competence, intellectual and cognitive capacities, they can easily adopt new technologies once they perceive them easy to use.

For both groups, perceived usefulness was found to be the most significant factor affecting behavioral intention to adopt, which is in agreement with what TAM postulates. This outcome suggests that physicians have the propensity to concentrate on the usefulness of telemedicine in their daily activities. Therefore, for telemedicine to be adopted, decision makers have to prove that this technology serves the needs of modern healthcare.

Image and perceived voluntariness of use showed no positive impact on behavioral intention to adopt telemedicine. Contrary to the hypothesis, perceived voluntariness of use had a significant and negative impact on behavioral intention to adopt for group A. This result may be explained by the fact that these physicians, due to their heavy load of research and practice, have less time to assess new technologies related to their work and they probably prefer that someone else do the legwork for them. 


\section{Conclusion and limitations}

The goal of this research was to improve the understanding of the adoption of telemedicine technology among physicians. The verified model has important implications for academics as well as for IS practitioners. A number of important findings emerged from this study. Overall we can say that this adapted model from TAM and from other frameworks provides some insightful information about the reactions a group of potential adopters of technology will have.

Perceived usefulness of telemedicine has been proven to have a strong impact on physicians' behavioral intention to adopt it, for both groups of physicians. The results imply that it is crucial that IS practitioners do the necessary work to enhance physicians' perception of telemedicine usefulness. Hospital decision makers will have to create more opportunities for physicians to voice their opinions on the usefulness of information technologies. This way, the healthcare professionals will have a more active role in the decision-making process when evaluating new technologies. These physicians need to be reassured that technology will never replace their hands-on expertise. Image had no impact on physicians' behavioral intention to adopt telemedicine, meaning that external pressure has nothing to do with their decision to adopt or not this technology. On the other hand, for the group of physicians doing teaching and research, their perceived voluntariness had a negative impact on their intention to adopt telemedicine. This may signify that they trust the hospital's IS professionals to choose appropriate technologies that will help them improve the quality of their healthcare delivery. As long as physicians perceive their usefulness for their work and their ease of use with no major efforts, they will be inclined to adopt them.

The research model also helped to identify the differences when a group is exposed to training or not before a new technology is implemented. Since physicians from group B have already received some training, they did not identify the perceived effort and persistence construct as one that could affect their perception of the ease of use of telemedicine. They already know what are the necessary efforts to be put into learning this technology. Besides that aspect, they also have been exposed to its ease of use throughout the training, even if they have not used it yet. Results obtained with the model, reflect the fact that physicians from group A did 
not receive any training with the technology. Since they do not know exactly what to expect from the technology, they believe it will be necessary to put some effort into learning it.

This research has some limitations. Responses to this study were voluntary, therefore prone to self-selection biases; only physicians who were interested in telemedicine technology likely filled in the questionnaire. More research needs to be done to further confirm the validity of the model presented in this study. Longitudinal studies that examine how beliefs of the same user evolve over time would also provide a more thorough test of how the determinants of behavioral intention to adopt telemedicine, namely perceived ease of use, perceived usefulness, perceived voluntariness of use and image change, over time.

\section{References}

Adams, D. A., Nelson, R. R. and Todd, P. A. "Perceived Usefulness, Ease of Use and Use Information Technology”, MIS Quarterly, 1992, Vol. 16, No. 2, pp. 227-250.

Agarwal, R., Prasad, J. “Are Individual Differences Germane to the Acceptance of New Information Technologies", Decision Sciences, 1999.

Allen, A., Hayes, J., Sadasivan, R., Williamson, S.K., Wittman, C.A. "A Pilot Study of the Physician Acceptance of Tele-oncology”, Journal of Telemedicine and Telecare, 1995, Vol. 1, pp. 34-37.

Bandura, A. Social Learning Theory, Prentice-Hall, Englewood Cliffs, 1977.

Bandura, A., Schunk, D. H. “Cultivating Competence, Self-Efficacy and Intrinsic Interest through Proximal Self-Motivation", Journal of Personality and Social Psychology, 1981, Vol.41, pp.586-598.

Bashshur, R., Sanders, J.H., Shannon, G.W. Telemedicine: Theory and Practice, Springfield, Illinois, 1997.

Cassel, C., Hackl, P. and Westlund, A.H. "Robustness of Partial Least-Squares Method for Estimating Latent Variable Quality Structures", Journal of Applied Statistics, 1999, Vol. 26, No. 4, pp. 435-446. 
Chang, M, K. "Predicting Unethical Behavior: A Comparison of the Theory of Reasoned Action and the Theory of Planned Behavior", Journal of Business Ethics, 1998, Vol. 17, pp. 1825-1834.

Chau, P.Y.K. “An Empirical Assessment of a Modified Technology Acceptance Model”, Journal of Management Information Systems, 1996, Vol. 13, No. 2, pp. 185-20.

Chin, W.W., Fee, T. PLS Graph Software, 1995 v. 2910208

Chin, W.W., Marcolin, B.L. and Newsted, P.R. “A Partial Least Squares Latent Variable Modeling Approach for Measuring Interaction Effects: Results from a Monte Carlo Simulation Study and Voice Mail Emotion/Adoption Study", Proceedings of International Conference on Information Systems. Cleveland 1996.

Compeau, D.R., Higgins, C.A., Huff, S. "Social cognitive theory and individual reactions to computing technology: A longitudinal study" MIS Quarterly, 1999, Vol. 23, No. 2, pp. 145-158.

Compeau, D.R., Higgins, C.A. “Computer Self-Efficacy: Development of a Measure and Initial Test”, MIS Quarterly, 1995, Vol.19, pp.189-211.

Davis, F. D. "Perceived Usefulness, perceived ease of use and User Acceptance of Information Technology", MIS Quarterly, 1989, pp.319-340.

Davis, F. D., Bagozzi, R. P., Warshaw, P. R. "User Acceptance of Computer Technology: A Comparison of Two Theoretical Models", Management Science, 1989, pp.982-1003.

Davis, F.D. "User Acceptance of Information Technology: System Characteristics, User Perceptions and Behavioral Impacts", Int. J. Man-Machine Studies, 1993, Vol. 38, pp. 475-487.

Dillon, A., Morris, M. "User Acceptance of Information Technology: Theories and Models”, Annual Review of Information Science and Technology, 1996, Vol. 31, pp. 3-32.

Filler, R. "Healthcare in the $21{ }^{\text {st }}$ Century: Virtual Hospitals, Tele-Homecare and Robots", Hospital Quarterly, 1999, pp. 68-70. 
Fishbein, M., Ajzen, I. Belief, Attitude, Intention and Behavior: An Introduction to Theory and Research, Addison-Wesley, Massachusetts 1975.

Fornell, C. and Larker, D. "Evaluating Structural Equation Models with Unobservable Variable and Measurement Error", Journal of Marketing Research, 1981, Vol. 18, pp.39-50.

Hair, J.F., Anderson, R.E., Tatham, R.L. and Black, W.C. Multivariate Data Analysis with Readings, $3^{\text {rd }}$ edition, New York MacMillan, 1992.

Hu, P.J., Chau, P.Y.K, Sheng, O.R.L, Tam, K.Y. "Examining the Technology Acceptance Model Using Physician Acceptance of Telemedicine Technology”, Journal of Management Information Systems, 1999,Vol.16, No.2, pp.91-112.

Hulland, J. "Use of Partial Least Squares (PLS) in Strategic Management Research: A Review of Four Recent Studies”, Strategic Management Journal, 1999, Vol. 20, pp. 195-204.

Igbaria, M., Zinatelli, N., Cragg, P. and Cavaye, A. "Personal Computing Acceptance Factors in Small Firms: A Structural equation model”, 1997, MIS Quarterly,

Jackson, C. M., Chow, S., Leitch, R.A. "Toward an Understanding of the Behavior Intention to Use an Information System”, Decision Sciences, 1997, Vol. 28, No. 2, pp. 357-387.

Karahanna, E., Straub, D. W., Chervany, N.L. “Information Technology Adoption Across Time: Across Sectional Comparison of Pre-Adoption and Post-Adoption Beliefs", MIS Quarterly, 1999, Vol. 23, No. 2, pp. 183-213.

Marakas, M.G., Yi, M.Y. and Johnson, R.D. “The Multilevel and Multifaceted Character of Computer SelfEfficacy: Toward Clarification of the Construct and an Integrative Framework for Research", Information Systems Research, 1998, Vol. 9, No. 2, pp. 126-162.

Mathieson, K. "Predicting User Intentions: Comparing the Technology Acceptance Model with the Theory of Planned Behavior", Information Systems Research, 1991, Vol. 2, No. 3, pp. 173-191. 
Moore, G.C, Benbasat, I. "Development of an Instrument to Measure the Perceptions of Adopting an Information Technology Innovation”, Information Systems Research, 1991, Vol. 2, No. 3, pp. 192-211.

Nunnally, J. Psychometric Theory, $1^{\text {st }}$ edition, New York, McGraw-Hill, 1967.

Picot, J. "Sector Competitiveness Frameworks- Telehealth Industry, Part 1 - Overview and Prospects", Industry Canada, 1998.

Rogers, E. M. Diffusion of Innovations, $4^{\text {th }}$ edition, The Free Press, New York, 1995.

Succi, M.J., Walter, Z.D. "Theory of User Acceptance of Information Technologies: An Examination of Healthcare Professionals", Proceedings of the $32^{\text {nd }}$ Annual Hawaii Conference on System Sciences, Maui, 1999.

Taylor, S., Todd, P.A. "Understanding Information Technology Use: A Test of Competing Models", Information Systems Research, 1995, Vol. 6. No. 2, pp.147-176.

Venkatesh, V. Davis, F.D. “A Model of Antecedents of Perceived Ease of Use: Development and Test", Decision Sciences, Vol.27, No.3, Summer 1996. 